\title{
Did Javal measure eye movements during reading?
}

\author{
Nicholas J. Wade \\ University of Dundee
}

\author{
Benjamin W. Tatler \\ University of Dundee
}

\begin{abstract}
Louis-Émile Javal is widely credited as the first person to record eye movements in reading. This is so despite the fact that Javal himself never made that claim but it is perpetuated in contemporary text books, scientific articles and on the internet. Javal did coin the term 'saccades' in the context of eye movements during reading but he did not measure them. In this article we suggest that a misreading of Huey's (1908) book on reading led to the misattribution and we attempt to dispel this myth by explaining Javal's contribution and also clarifying who did initially describe discontinuous eye movements during reading.
\end{abstract}

Keywords: saccades, eye movements, jerks, history, Javal, Hering,

Lamare

Louis-Émile Javal wrote a series of papers on the visual processes involved in reading (Javal, 1878a, b, c, $1879 \mathrm{a}, \mathrm{b}, \mathrm{c}, \mathrm{d}, \mathrm{e})$. He is now widely credited as being the first writer to use the term 'saccades' to refer to rapid eye movements. Later writers, like Huey (1908) and Woodworth (1938), implied that Javal observed and measured saccades during reading. However it now seems likely that Javal's contribution to the early understanding of saccadic eye movements may be somewhat less than previously thought (see Tatler and Wade, 2003; Wade and Tatler, 2005; Wade, Tatler and Heller, 2003). We have argued that the popular misattribution of saccadic measurement and discovery to Javal was a consequence of the less careful wording of Huey's now-classic book The psychology and pedagogy of reading (1908). Subsequent researchers have drawn too heavily on Huey's account rather than returning to the original articles by Javal.

Many attempts were made to measure eye movements throughout the nineteenth century, although concern was with ocular torsion and nystagmus rather than reading (see Wade, 2007; Wade and Tatler, 2005). Most employed afterimages and compared their displacements to real images. Javal (1878c) used this technique to establish that the eye glided horizontally across lines of text with no vertical deviations. In the context of reading, Landolt (1891) observed eye movements directly, and Tscherning (1898), Javal's successor as director of the ophthalmology laboratory at the Sorbonne, described
Lamare's studies of saccadic eye movements. A mechanical means of measuring nystagmus was tried by Rählmann (1878) and later Ahrens (1891) applied similar methods to reading. He attempted to record eye movements directly by placing an ivory cup on the cornea and attaching a bristle to it; movements of the eye could be registered by the displacements of the bristle on a revolving smoked drum. Ahrens was not able to obtain any detailed recordings of eye movements, but his method was adopted by Delabarre (1898) and Huey (1898, 1900) to record eye movements during reading. Erdmann and Dodge (1898) observed readers' eyes through a mirror and noted their discontinuities; they did not cite Javal. In his second article, Huey (1900) wrote:

"Lamare, working with Javal, finding that the movement of the eye in reading was not continuous, but by little jerks (par saccades), devised the following method for counting these: A blunt point placed on the upper eyelid of the reader put in action a microphone, whose sound, transmitted by a rubber tube, made known each movement to the ear of the experimenter the short reading jerks causing a brief sound, while the extensive movements made in passing from the end of the line to the commencement of the next, caused a more prolonged sound.” (p. 285)

It might be an overstatement to refer to the misattribution as a myth, but its persistence is puzzling. Measurements of eye movements during reading were 
carried out in Javal's laboratory by Lamare and reported in passing by Javal (1879e). Earlier in the same year, Hering (1879a) had used a similar technique with greater elegance to describe discontinuous eye movements during reading. Our intention in the earlier articles was to draw attention to Javal's own accounts of his reading research in the hope that the early history of eye movement measurement would be reported more accurately. The quotations that follow, all of which are from the last few years, provide abundant evidence of our previous failure in this desire.

\section{Perpetuating the myth?}

Contemporary textbooks on perception might be forgiven for failing to reflect nuances in the history of eye movement research. However, we continue to be surprised that texts specifically devoted to eye movements persist in ascribing to Javal credit for the first measurements of the ways the eyes move during reading which we have not been able to find in his articles. In some cases, truly novel techniques have been attributed to him. We give below some recently published statements attributing the measurement of saccades to Javal, and then we return to Javal's own writing on reading.

"By 1879, experiments undertaken by Emile Javal in France at the University of Paris had led to the discovery that the eyes of a reader do not move smoothly over a line of print, as one might think, but actually take little leaps across the line being read." (Monaghan, 2007, p. 10)

"Until the research of Emil Javal (1839-1907), the French oculist, it had been believed that the eyes move across text in one continuous and smooth movement." (Reed and Meyer, 2007, p. 162)

"Experiments to crack open the mysteries of the reading process appear to have advanced in 1879 when French ophthalmologist Louis Émile Javal suceeded in measuring eye movement with electronics... Javal's experiment was carried out by connecting the eyelid to an electric circuit then counting the series of sounds produced in a microphone by each eye movement." (Currell, 2007, p. 347)
"His [Javal's] discovery was a deceptively simple one, observed with a mirror: that the passage of the eyes across a line of text is not continuous, but instead broken into a succession of pauses (later termed 'fixations') and rapid leaps, which would come to be called 'saccades', a reference to the sudden jerking of a ship's sail when caught by wind." (Dames, 2007, p. 212)

"In some of the first empirical studies, Javal [1879] used mirrors to observe the eye movements of subjects while reading, and was the first to note that the eyes moved in a series of "jerks". These fixations were counted by placing a microphone on a closed eyelid while the subject read monocularly. Each time the bulge of the moving cornea bumped the microphone, a saccade could be counted, according to Lamare and Javal [cited in Tinker, 1928].” (Richardson and Spivey, 2008, p. 1026)

"The first era extended from Javal's initial observations concerning the role of eye movements during reading (see Huey, 1908) until about 1920." (Rayner, 2009, p. 1)

The situation is only amplified by entries on the internet, which have not passed through the filter of reviewing, as journal articles have (see Wade, 2001). One example from Wikipedia is given below.

"Eye movements during reading were first described by the French ophthalmologist Louis Émile Javal in the late 19th century. He reported that eyes do not move continuously along a line of text, but make short rapid movements (saccades) intermingled with short stops (fixations). Javal's observations were characterised by a reliance on naked-eye observation of eye movement in the absence of technology.... In 1879, the French ophthalmologist Louis Émile Javal used a mirror on one side of a page to observe eye movement in silent reading, and found that it involves a succession of discontinuous individual movements for which he coined the term saccades." http://en.wikipedia.org/wiki/Eye_movement_in_langu age_reading (downloaded 17th November 2008)

\section{Javal's studies of reading}

We have not been able to find evidence of the above sentiments in Javal's writing. Of his eight papers on read- 
ing, only two discussed eye movements in any detail. Javal (1879e) reasoned that the eye made no vertical movements during reading: "If, during reading, we maintain perfect immobility of the book and the head, the printed lines come to be painted successively on the same parts of the retina, while the spaces between the lines constantly fall upon the same parts of the retina" (p. 246). Moreover, Javal seems to have been of the opinion that the eye glides smoothly along the line during reading:

"gaze glides along a line slightly higher than the centre of the characters. The reason for this is easy to see: if gaze simply glides horizontally, complicated and useless movements are avoided, and the chosen position of the horizontal is determined by the structure of the typographic characters" (1878c, p. 251).

It is somewhat ironic that not only does it appear that Javal did not make the measurements of saccades ascribed to him by later researchers, but also that the opinion expressed by Javal in the quotation above is antithetic to that which history has endowed him with.

While these examples suggest that Javal may not have possessed as keen an awareness of the saccadic nature of eye movements as Huey bestowed upon him, he did recognise the necessity to measure eye movements objectively and made several attempts to do so. Javal (1878c) tried to examine eye movements during reading by observing the movements of an afterimage, but found that the technique was difficult to apply because of the contrast between the letters on the page and the afterimage. He also considered attaching a feather to the eye so that movements could be recorded on a smoked drum, and he attempted (unsuccessfully) to measure the deflections of light from a mirror attached to his eye:

"It does not appear impossible to me to be able to carry out the same demonstration in the context of an objective experiment, which would consist of reading by a one-eyed person whose bad eye has retained good mobility, to which one could attach a feather for registering its movements on a smoked cylinder; I am certain that one would thus note the absence of vertical movements of the eye during reading" (Javal, 1878 c, p. 250).

He did mention saccades in a footnote on the penultimate page of the final article of his series in 1879 . How- ever, this was a reference to work in his laboratory by Lamare, rather than by Javal himself:

"Following the research of M. Lamare in our laboratory, the eye makes several saccades during the passage over each line, about one for every 15-18 letters of text. It is probable that in myopes the eye reacts with a rapid change in accommodation with every one of these saccades" (1879e, p. 252).

It seems likely that it is from this footnote that Lamare's work has become mistakenly attributed to Javal. Certainly Javal did use the term 'saccade' in his final article in 1879 , both in the footnote mentioned above and on the preceding page, where he referred to saccades when describing rapid changes in accommodation during reading:

"Considering our specific ideas about the mechanism of accommodation, it is not surprising that the series of saccades imprinted to the choroids by the ciliary muscles of myopes have the effect of augmenting their disability" (Javal, 1879e, p. 251).

These are the earliest uses of the term saccade to describe eye movements that we have encountered and Javal therefore deserves due credit for first using the term. While Javal did use the term 'saccade', it was at the time an unremarkable French word, in common usage, meaning 'jerk' or 'twitch'. That the term came to be adopted widely in English was due largely to Dodge (1916).

\section{Creating the myth?}

The earliest report of Javal's work in English that we have found was Huey (1898), but this was concerned with eye fatigue in reading. In a later article, Huey (1900) elaborated on Javal's description of eye movements during reading. Huey also made reference to Lamare's (1892) article (although the date was given as 1893), giving a brief account of Lamare's auditory method of detecting eye movements. In Huey's (1901) third article on reading Javal was cited only in the context of type size. Several years later, in a book regarded as a classic of psychology, Huey (1908) provided an historical account of research on eye movements and reading. It is in this book that Huey implied Javal was the founder of research in this area: 
"Professor Javal, of the University of Paris, seems, as has been said, to have been the first to note the actual character of the eye's movements in reading... While not all of Professor Javal's observations are conclusive, he deserves more than does anyone else the credit for making the initial discoveries in this field, and for initiating a considerable number of later studies" (Huey, 1908, p. 18).

Moreover, Huey implied that the experiments reported by Javal had been conducted by him. Most subsequent writers cite Huey's book as the authoritative source for the early history of eye movement recording. For example, Woodworth (1938), in the chapter on eye movements in his influential textbook noted: "The most important single fact, it is true, was discovered by Javal (1878) without any more special technique than simply watching the eye of a school child who was reading" ( $p$. 577). Later in his chapter on reading Woodworth observed: "Javal (1878) by watching the reader's eyes, found that they moved along the lines not with a smooth, steady movement, but in a series of jumps or 'saccades' separated by fixation pauses" (1938, p. 715). Acceptance of the accounts by Huey and Woodworth has deflected students of vision from attributing the first measurements of eye movements to those who conducted the experiments - Hering and Lamare.

\section{The unsung saccadic heroes}

Ewald Hering is the principal unsung hero in describing eye movement during reading. He was an authority on binocular eye movements and he had long studied them using the traditional afterimage method. Indeed, in 1879 he published a long chapter on their involvement in the perception of space (Hering, 1879b; 1942). In the prepublication period for this chapter, he wrote a short article employing a radically different technique. Hueter (1878) had made a passing observation that sounds could be heard when a rubber tube was applied to the closed eyelid. He suggested that the sound was generated by blood flow through the capillaries in the lids. Hering (1879a) argued that the sounds were a consequence of muscle contractions and conducted a series of observations to confirm this. He attached a rubber tube to a cigar holder and listened to the sounds produced when it was placed on the eyelids: he "heard a surprisingly strong and whirring roar" (p. 137). When he placed the device on the eye of curarised dogs or rabbits the sounds ceased even though the blood flow continued. Having determined that the sounds reflected muscular contractions, Hering applied the technique to the eye lid of an open eye. Even when he tried to keep his eyes still he heard the sounds: "Throughout one's observations, one hears quite short, dull clapping sounds, which follow each other at irregular intervals" (p. 145). Hering was able to use his experience with afterimages to establish that the sounds were correlated with eye movements by comparing them: "every clapping sound corresponds to a displacement of the afterimage" (p. 145). This was confirmed by movements of floaters, which occurred with the clapping sounds.

Hering's study is significant not only because he compared afterimage movement to the sounds of muscular movements, but also because he applied the technique to reading: "One can observe the clapping sounds very clearly during reading. Although the eyes appear to glide steadily along the line, the clapping sounds disclose the jerky movement of the eyeball" (1879a, p. 146). The sounds were louder when the eye moved from the end of one line to the beginning of the next and they were evident when observers read lines of text but disappeared if they were instructed to fixate a stationary target. It is also of note that he used the term 'jerks' (Rucke in German) because this is equivalent to using the term 'saccades' to describe rapid eye movements if he had been writing in French.

While much has been written about Hering (see Baumann, 2002), very little seems to be known about $\mathrm{M}$. Lamare, and we would welcome any further information about him. He did not publish an account of his experiments until over a decade after they were mentioned by Javal (Lamare, 1892), and later still Javal (1905) himself assigned the credit to Lamare rather than making a claim for his own research:

"In an important work conducted by M. Lamare in my laboratory, he demonstrated that the horizontal movements of the eyes during reading are by no means continuous, but proceed by saccades" (Javal, 1905, p. 127, original italics).

Lamare described several methods he applied to study the number of such saccades along a line of text. The first method was based on counting: he counted the number of letters he could read in one minute and divided that by the estimated number of pauses made. The average 
value he arrived at was ten letters per saccade. He then tried to determine, during fixation, the extent of letter recognition in the periphery. The third method involved counting the number of distinct movements the eye made along a line. It was in this context that he described how the discontinuous eye movements can be observed in a reader, or felt by placing a finger over the closed eye when reading with the open one: "An assistant can see these movements. He can feel them with a finger over the lid of a closed eye" (Lamare, 1892, p. 357, original italics).

Lamare was not satisfied with using observation or touch to count the eye movements and so constructed apparatus that could record the movements and pauses, and the method he adopted bore a striking similarity to that employed by Hering (1879a): "The method that gives the best results is one by which the movements are heard via a drum with an ebonite membrane in the centre and to which a small tube is attached; the tube is in contact with the conjunctiva or eyelid and is connected to both ears by rubber tubes... The apparatus yields distinctive sounds which an assistant can count and add, and note for each line. The return movement of the eyes to the beginning of a line gives a longer and louder noise that is easy to recognise; one counts the number of saccades from the start of the line to be able to note the number of divisions that occur in a line" (1892, p. 357, original italics). This was an indirect calculation based on the assumption that the saccades were equal in length: by noting the number of letters on a line, Lamare was able to calculate the average size of saccades; concluding that about ten letters must be read in each pause (which Lamare referred to as sections) between the eye movements. He concluded: "Although the results of this research are incomplete and do not support any theory, they can perhaps serve to encourage the extension of these important investigations" (p. 361). Thus, Lamare was recording the number of saccades during reading a line of text, not their extent. A crucial and insightful aspect of this paper was to compare the number of letters read per fixation for text displayed at different distances. Lamare found that: "Regardless of the DISTANCE at which one reads from the same text (from $0.30 \mathrm{~m}$ to $1 \mathrm{~m}$ ), the number of letters per section DOES NOT VARY' (Lamare, 1892, p. 361, original italics and capitals). Lamare was recording the number of saccades during reading a line of text, not their extent. Inferences about the latter could be made as an indirect calculation based on the number of letters on a line and on the assumption that the saccades were equal in length. It would appear that Lamare's research on eye movements during reading has been overshadowed by Javal's description of it. Citations of Lamare's work have not been consistent.

We do not wish to suggest that the studies of Hering and Lamare have been ignored completely. Carpenter (1977) mentioned Hering's listening method, referring to it as bizarre and simple, but Carpenter did not relate it to reading. O'Regan (1990) placed Lamare before Javal in describing early studies of eye movements and reading. Nor do we wish to imply that our earlier observations have been overlooked (see Eggert, 2007; Legge, 2006).

\section{Conclusion}

Hering and Lamare measured eye movements during reading using similar methods. In 1879, Hering described his afterimage and sounding studies and Javal made brief reference to Lamare's unpublished experiments. Javal should be credited for introducing the term saccade, but he did not measure eye movements during reading himself. Science should not be like journalism and follow the maxim 'when the myth is better known than the truth, publish the myth'. Whether drawing attention to this misattribution regarding Javal's part in the early history of eye movement research will influence further repetitions of it remains to be seen.

\section{Acknowledgments}

We wish to express our thanks to Françoise Vitu and an anonymous reviewer for comments on an earlier version of this article.

\section{References}

Ahrens, A. (1891). Die Bewegung der Augen beim Schreiben. Rostock: University of Rostock.

Baumann, C. (2002). Der Physiologe Ewald Hering (1834-1918). Frankfurt: Hänsel-Hohenhausen.

Carpenter, R. H. S. (1977). Movements of the eyes. London: Pion. 
Currell, S. (2007). Streamlining the eye: speed reading and the revolution of words, 1870-1940. In C. R. Acland (Ed.) Residual media. Minneapolis: University of Minnesota Press. pp. 344-360.

Dames, N. (2007). The physiology of the novel: reading, neural science and the form of Victorian fiction. Oxford: Oxford University Press.

Delabarre, E. B. (1898). A method of recording eye movements. American Journal of Psychology, 9, 572574

Dodge, R. (1916). Visual motor functions. Psychological Bulletin, 13, 421-427.

Eggert, T. (2007). Eye movement recording methods. In A. Straube \& U. Büttner (Eds.) Neuroophthalmology: Neuronal control of eye movements. Basel: Karger. pp. 15-34.

Erdmann, B., \& Dodge, R. (1898). Psychologische Untersuchungen über das Lesen auf experimenteller Grundlage. Halle: Niemeyer.

Hering, E. (1879a). Über Muskelgeräusche des Auges. Sitzberichte der kaiserlichen Akademie der Wissenschaften in Wien. Mathematischnaturwissenschaftliche Klasse, 79, 137-154.

Hering, E. (1879b). Der Raumsinn und die Bewegungen des Auges. In L. Hermann (Ed.) Handbuch der Physiologie, Vol. 3, Part 1 Physiologie des Gesichtssinnes. Leipzig: Vogel. pp. 343-601.

Hering, E. (1942). Spatial sense and movements of the eye. Trans C. A. Raade. Baltimore: American Academy of Optometry.

Hueter, C. (1878). Versuche zur Begründung einer Auscultation für chirurgisch-diagnostische Zwecke. Centralblatt für die medicinischen Wissenschaften, No. 51.

Huey, E. B. (1898). Preliminary experiments in the physiology and psychology of reading. American Journal of Psychology, 9, 575-586.

Huey, E. B. (1900). On the psychology and physiology of reading. I. American Journal of Psychology, 11, 283302.

Huey, E. B. (1901). On the psychology and physiology of reading. II. American Journal of Psychology, 12, 292312 .
Huey, E. B. (1908). The psychology and pedagogy of reading. New York: Macmillan.

Javal, L. É. (1878a). Essai sur la physiologie de la lecture. Annales d'Oculistique, 79, 97-117.

Javal, L. É. (1878b). Essai sur la physiologie de la lecture. Annales d'Oculistique, 80, 135-147.

Javal, L. É. (1878c). Essai sur la physiologie de la lecture. Annales d'Oculistique, 80, 240-274.

Javal, L. É. (1879a). Essai sur la physiologie de la lecture. Annales d'Oculistique, 81, 61-73.

Javal, L. É. (1879b). Essai sur la physiologie de la lecture. Annales d'Oculistique, 81, 157-162.

Javal, L. É. (1879c). Essai sur la physiologie de la lecture. Annales d'Oculistique, 82, 72-81.

Javal, L. É. (1879d). Essai sur la physiologie de la lecture. Annales d'Oculistique, 82, 159-170.

Javal, L. É. (1879e). Essai sur la physiologie de la lecture. Annales d'Oculistique, 82, 242-253.

Javal, L. É. (1905). Physiologie de la lecture et de l'écriture. Paris: Alcan.

Lamare, M. (1892). Des mouvements des yeux dans la lecture. Bulletins et Mémoires de la Société Française d'Ophthalmologie, 10, 354-364.

Landolt, E. (1891). Nouvelle recherches sur la physiologie des mouvements des yeux. Archives d'Ophthalmologie, 11, 385-395.

Legge, G. E. (2006). Psychophysics of reading in normal and low vision. London: Routledge.

Monaghan, E. J. (2007). Scientific research and progressive education: Contexts for the early reading pioneers 1870-1956. In S. E. Israel \& E. J. Monaghan (Eds.). Shaping the reading field. The impact of early reading pioneers, scientific research, and progressive ideas. Newark, DE: International Reading Association. pp. 1-32.

O'Regan, J. K. (1990). Eye movements and reading. In E. Kowler (Ed.) Eye movements and their role in visual and cognitive processes. Amsterdam: Elsevier. pp. 395-453.

Rählmann, E. (1878). Über den Nystagmus und seine Ätiologie. Archiv für Ophthalmologie, 24, 237-242. 
Rayner, K. (2009). Eye movements in reading: models and data. Journal of Eye Movement Research, 2(5), 2, $1-10$.

Reed, J. B., \& Meyer, R. J. (2007). Edmund Burke Huey (1870-1913): A brief life with an enduring legacy. In S. E. Israel and E. J. Monaghan (Eds.). Shaping the reading field. The impact of early reading pioneers, scientific research, and progressive ideas. Newark, DE: International Reading Association. pp. 159-175.

Richardson, D. C., \& Spivey, M. J. (2008) Eye tracking: characteristics and methods. In G. E. Wnek \& G. N. Bowlin (Eds.) Encyclopedia of biomaterials and biomedical engineering. Vol. 2. $2^{\text {nd }}$. Ed. London: Informa Healthcare. pp. 1028-1032.

Tatler, B. W., \& Wade, N. J. (2003). On nystagmus, saccades and fixations. Perception, 32, 167-184.

Tscherning, M. H. E. (1898). Optique physiologique. Paris: Carré and Naud.

Wade, N. J. (2001). Websights. Perception, 30, 261-262.

Wade, N. J. (2007). Scanning the seen: vision and the origins of eye movement research. In R. P. G. van Gompel, M. H, Fischer, W. S., Murray, \& R. L. Hill (Eds.). Eye Movements: A Window on Mind and Brain. Oxford: Elsevier. pp. 31-61.

Wade, N. J., \& Tatler, B. W. (2005). The moving tablet of the eye: the origins of modern eye movement research. Oxford: Oxford University Press.

Wade, N. J., Tatler, B. W., \& Heller, D. (2003). Dodgeing the Issue: Dodge, Javal, Hering and the Measurement of Saccades in Eye Movement Research. Perception, 32, 793-804.

Woodworth, R. S. (1938) Experimental psychology. New York: Holt 